\title{
Universitarios detenidos organizados: una cuña en la solidez de la cárcel
}

Analia Umpierrez ${ }^{1}$

\section{Resumen}

Se presenta y analiza aquí el modo en que los estudiantes participantes de centros universitarios con sede en cárceles de la Provincia de Buenos Aires, Argentina, aportaron sus saberes expertos para afrontar la contingencia del encierro en el encierro en el período de aislamiento social, preventivo y obligatorio por pandemia entre los meses de marzo y diciembre del año 2020. En las prisiones argentinas se desplegaron tensiones que devinieron en desbordes y muertes, pero también se relevaron prácticas de gestión de la violencia desde el trabajo y el liderazgo de los detenidos universitarios. En este contexto es el propio gobierno de la cárcel el que entró en juego. La construcción de poder por parte de estos colectivos organizados y el final anunciado la dispersión de los actores en diferentes unidades penales con la paulatina vuelta a la nueva normalidad, da cuenta de la peligrosidad que las fuerzas de seguridad más conservadoras ven en esta forma de gestión. Se apela a registros etnográficos, publicaciones y documentos recogidos en el período mencionado.

Palabras clave: Estudiantes universitarios detenidos. Poder. Gestión de la cárcel.

\section{Estudantes universitários presos organizados: uma cunha na solidez da prisão}

\section{Resumo}

É aqui apresentada e analisada a forma como os alunos participantes de centros universitários sediados em prisões da Província de Buenos Aires, Argentina, contribuíram com seus conhecimentos periciais para enfrentar a contingência do confinamento em reclusão no período social, preventivo e de isolamento. devido à pandemia entre os meses de março e dezembro de 2020. Nas prisões argentinas, surgiram tensões que resultaram em transbordamentos e mortes, mas as práticas de gestão da violência também foram reveladas no local de trabalho e na liderança de detentos universitários. Nesse contexto, é o próprio governo prisional que entra em ação. A construção do poder por estes grupos organizados e o anunciado fim da dispersão dos actores nas diferentes unidades penais com o regresso gradual à nova normalidade, mostra o perigo que as forças de segurança mais conservadoras veem nesta forma de gestão. São utilizados registros etnográficos, publicações e documentos coletados no período mencionado.

Palavras chave: Estudantes universitários presos. Poder. Gestão de prisão.

\section{Organized detained university students: a wedge in the solidity of the prison}

\begin{abstract}
The way in which the participating students from university centers based in prisons in the Province of Buenos Aires, Argentina, contributed their expert knowledge to face the contingency of confinement in confinement in the period of social, preventive and social isolation is presented and analyzed here. mandatory
\end{abstract}

1 Dra. en Educación. Profesora Titular e investigadora de la Facultad de Ciencias Sociales de la Universidad Nacional del Centro de la Provincia de Buenos Aires (UNICEN), Argentina. E-mail: aumpierr@soc.unicen.edu.ar 
due to pandemic between the months of March and December 2020. In Argentine prisons tensions unfolded that resulted in overflows and deaths, but violence management practices were also revealed from the workplace and the leadership of university detainees. In this context, it is the prison government itself that came into play. The construction of power by these organized groups and the announced end of the dispersal of the actors in different penal units with the gradual return to the new normal, shows the danger that the most conservative security forces see in this form of management. . Ethnographic records, publications and documents collected in the mentioned period are used.

Keywords: University students arrested.Power- jail government.

\section{Presentación y recorrido propuesto}

La pandemia y el aislamiento social preventivo y obligatorio (ASPO) abrieron un escenario impensado mundialmente. Asimilar los límites, superar la desesperanza, la falta de horizontes y la desesperación que las condiciones de la detención generaban en la población de las cárceles de Argentina fue un gran desafío.

En los largos meses de marzo a diciembre del año 2020 - período del que se dará cuenta muy a grandes rasgos en el presente trabajo- se vivieron situaciones críticas en la sociedad argentina y en nuestro foco de interés, las cárceles de la Provincia de Buenos Aires. En esos espacios, en los primeros meses en los que el aislamiento fue estricto y podría decirse, que se detuvo el país, la desazón y la desesperación fueron moneda corriente al interior de los penales.

Pondremos la mirada dos momentos, a nuestro entender críticos y directamente vinculados entre sí.

La propuesta es colocarlos de inicio como aquellas escenas que nos permiten interrogar qué sucedió en el entre tiempo al interior de la cárcel: en el período transcurrido entre las primeras manifestaciones sucedidas en las cárceles del país, el silencio y ausencia de respuestas por parte de la Justicia y del propio poder Ejecutivo y la explosión de violencia cuando el ASPO comienza a cambiar a Dis- tanciamiento Social, Preventivo y Obligatorio (DISPO) con apertura a actividades comerciales, sociales, culturales y recreativas y se habilitan las visitas en las cárceles de la provincia.

(...) en marzo, se prohibieron las visitas, lo que contribuyó al estallido de motines en las cárceles de Bouwer (Córdoba, 21 de marzo), Coronda y Las Flores (Santa Fe, 23 de marzo, cinco muertos), Florencio Varela y Batán (Buenos Aires, 23 de marzo) y Entre Ríos (Concepción del Uruguay, 24 de marzo). Sin embargo, el tema no se instaló en los medios sino un mes más tarde, el 24 de abril, cuando se produjo el motín del Complejo Penitenciario Federal de Devoto, la última cárcel de la ciudad de Buenos Aires. (GONZÁLEZ ALVO, 2020,pp: 123-124)

Una segunda explosión de violencia se registró sobre finales del mes de octubre tras el anuncio del regreso de las visitas y la marcha atrás sin aviso ni mediar diálogo, el día previo a la fecha anunciada:

En algunas unidades penitenciarias se vivieron momentos de violencia extrema, luego que se había llegado a un acuerdo para restituir las visitas. Represión a las protestas, traslados intempestivos y ataques a los centros educativos fueron la respuesta por parte de las fuerzas del Servicio Penitenciario. Asi sucedió en la Unidad Penal 48, del Penal de José León Suárez, donde se vivió una jornada de violencia y brutalidad, contra el CUSAM, Centro Universitario San Martín, espacio dentro del penal donde funciona la Universidad de San Martín. También el espacio educativo universitario de la Unidad Penal 31 de Florencio Varela, donde la Universidad de La Plata tiene trabajos educativos, fue atacado (Comunicado del CUSAM - 4/11/20) ${ }^{2}$.

En su carácter de Mecanismo Local de Prevención de la Tortura, la Comisión Provincial por la Memoria $(\mathrm{CPM})$ elaboró un informe que se presentó a las autoridades provinciales, sobre la brutal represión del Servicio Penitenciario Bonaerense durante las protestas del 31 de octubre y $1^{\circ}$ de noviembre y los días posteriores. Durante esos días, la CPM presentó 1.580 habeas corpus individuales y 21 acciones de carácter colectivo y decenas de denuncias penales para que se investiguen y sancionen las torturas perpetradas durante las protestas y también los días posteriores (...). Se estima que más de 1.500 personas sufrieron diferentes tipos de torturas (...) Se formularon decenas de denuncias penales solicitando se investiguen los hechos ocurridos, entre ellos la represión y actuación penitenciaria en los hechos,

2 Nota "CUSAM: tras la represión, la reconstrucción” 4/11/20 - disponible en https://www.marcha.org.ar/a-reconstruir-el-cusam 
y la destrucción e incendio de los Centros Universitarios y los traslados arbitrarios posteriores. (Las cursivas son nuestras - Gacetilla CPM 12/11/20) ${ }^{3}$.

Se propone aquí entonces, dar cuenta de algunas dinámicas relevadas en las cárceles de la Provincia de Buenos Aires que se sucedieron después de la primera manifestación de violencia a finales de marzo 2020 y hasta el comienzo de la reapertura de las cárceles en noviembre del mismo año.

Para ello se buscó contextualizar el devenir en la cárcel en este período a través de algunas escenas que permitan conformarse en analizadores institucionales (LAPASSADE, 1977 [1999]). El analizador es un "concepto básico del Análisis Institucional y su validación es la validación misma del método" (MANERO BRITOS, 2013,p.18) ${ }^{4}$. Vale señalar que "el analizador es un concepto político porque devela la relación de poder al interior del mismo o entre el grupo y su medio institucional" (FARES, 2010,p.3).

Para este trabajo se seleccionaron escenas institucionales y otras situaciones relevadas en el campo como analizadores naturales; se apelará a testimonios escritos ${ }^{5}$ que fueron publicados en el período en redes sociales y discursos orales emitidos en un programa de radio $^{6}$ a cargo de personas detenidas, mayoritariamente estudiantes universitarios y talleristas de años previos de las cuatro unidades penales en las que la Universidad Nacional del Centro de la Provincia de Buenos Aires (UNICEN) trabaja y que permiten poner en parte en luces y sombras algunas huellas o trazas (DIAMANT, CAZAS y DUHALDE, 2015) en el estudiantado universitario construidas en su tránsito por la universidad antes y durante el ASPO. Interesa aquí identificar y analizar los modos en que esos saberes permitieron construir respuestas diferentes a las que la cárcel como institución instala en su vida cotidiana: conflictividad, violencia física y simbólica, individualismo, crueldad, aislamiento, destrucción de humanidad. Asimismo se toman como fuentes publicaciones periodísticas e informes producidos por organismos de derechos humanos, entre otros en el período señalado.

El recorrido que se propone

-Presentar algunas consideraciones sobre la labor de la Universidad en la cárcel, la organización y funcionamiento de los centros universitarios y su gestión.

-Presentar algunas líneas de acción y tareas desplegadas en periodo de ASPO desde la universidad en la cárcel.

-Caracterizar las trazas de la presencia de la universidad en las prácticas y discursos de los estudiantes universitarios así como algunas tensiones que impactan en la vida misma de los centros universitarios y disputan sentidos a la cárcel.

\section{Cárceles en pandemia. Acerca de cómo las políti- cas se disputan en el territorio}

La presencia de la UNICEN en las cárceles se concreta en una jurisdicción que reunía para el año 2018 el 43\% del total de la población encarcelada del país (GONZÁLEZ ALVOS 2020) con una sobrepoblación del 113\% para 2019 según datos del Comité Contra la Tortura (CPM).

En el informe anual 2019 del CPM de la provincia de Buenos Aires (PBA), la población detenida en la jurisdicción alcanza 50.500 personas en cárceles y 4129 en comisarías. Además es necesario señalar que, se habrían dispuesto en la PBA para el período de análisis (marzo/noviembre 2020) prisiones domiciliarias para 800 detenidos (menos del dos por ciento) (GONZÁLEZ ALVO, 2020, p.126). Es decir que fue ínfima la cantidad de personas que obtuvie-

\footnotetext{
3 "A modo de ejemplo, el presidente del Centro de Estudiantes de la Unidad 31 fue trasladado a Magdalena y hoy se dispuso su traslado a Sierra Chica. Otro estudiante universitario de la Unidad 31 recibió varias heridas cortopunzantes provocadas por un agente penitenciario y se encuentra internado con pronóstico reservado; su familia se enteró recién dos semanas después de lo ocurrido". Informe completo disponible en https://www.comisionporlamemoria.org/la-cpm-pidio-que-se-investiguen-y-sancionen-las-multiples-torturas-penitenciarias/

4 En términos generales y reconociendo que hay perspectivas en su abordaje (; Lapassade 1977), consideramos aquí que el analizador es toda aquella persona, situación, acción, que deconstruye lo instituido de la institución. El análisis es aquí entendido como el "efecto analizador", el análisis es una acción de deconstrucción que tiene efectos mediatos e inmediatos, en función de las relaciones de poder, de autoridad, del saber de los participantes de toda la estructura oculta de la institución, revelada de manera más o menos virulenta por los analizadores (MANERO, ibid:19)

5 Para más detalles ver UMPIERREZ, 2020 C.

6 Se hace referencia al programa radial Telarañas en su séptima temporada que fue emitido por FM 90.1Radio Universidad y enteramente producido y grabado al interior de las cárceles.
} 
ron alguna medida alternativa a la prisión en tiempo de aislamiento social en cárceles donde primaba el hacinamiento, la sobrepoblación, la falta de acceso a la justicia, a la salud y a la alimentación. Con la suspensión de las visitas también se interrumpió en gran medida la llegada de alimentos, vestimenta, medicamentos e insumos básicos para el sostén de la vida en prisión que aportaban las familias.

La situación del aislamiento social preventivo y obligatorio (ASPO), conllevó además el cierre de los espacios cotidianos de trabajo académico, de extensión e investigación y la imposibilidad de mantener el vínculo con estudiantes universitarios y talleristas que asistían a las propuestas formativas que se ofrecían tras los muros.

Una particularidad que se dio en la jurisdicción PBA fue la autorización del uso de celulares y dispositivos electrónicos ${ }^{7}$ y la posterior reglamentación para su uso por parte del Servicio Penitenciario Bonaerense (SPB). Esto permitió que a partir de finales de marzo de 2020 se diera una mayor cercanía con las familias.

El celular y en especial el Whatsapp fueron las herramientas más exitosas para sostener el vínculo y las actividades planificadas desde la Universidad. Vale señalar que en las unidades penales no se cuenta con internet y solo una de ellas disponía de conexión a la red de internet en el aula universitaria.

Tal como en el afuera de la cárcel, el acceso a dispositivos y a telefonía está directamente vinculado a que haya quien lo provea, una familia que pueda entregar y mantener el gasto que implica ese acceso en el caso de las personas alojadas en la cárcel. La brecha digital se hizo más profunda en este contexto de aislamiento.

En los primeros meses del ASPO los diálogos que se entablaron desde la universidad fueron individuales, con aquellos estudiantes que ya tenían cercanía a través de estos canales y contaban con teléfonos con acceso a internet, $y$ lentamente se pudieron tejer vínculos más colectivos con aquellos con los que éstos y éstas compartían pabellón y no tenían dispositivos propios. La posibilidad de reunión de los y las estudiantes varió a lo largo del período recortado según la unidad penal, la situación de epidemiológica de la localidad y en cada cárcel en particular, por las decisiones internas de sus jefaturas.

\section{Las tareas de la Universidad en la cárcel, el estudiantado, la pandemia.}

\section{El papel que asumieron los Centros Universitarios y sus estudiantes organizados}

Los centros universitarios son los espacios propios, de autogestión y organización de los y las estudiantes detenidos (UMPIERREZ 2020, 2020b). Desde allí la universidad se proyecta, siempre con la participación necesaria de sus estudiantes privados de libertad, que son quienes no solo se vinculan desde su condición de matrícula estudiantil, sino y especialmente, como los referentes de la universidad en el territorio de la cárcel. Los Centros Universitarios son espacios neurálgicos que amplían y enraízan la presencia de la universidad en el territorio de la prisión. En el análisis de su despliegue cotidiano, se reconoce cómo estos centros universitarios se conforman en espacios que disputan poder tanto a la universidad como a la cárcel y en ese entrecruce se construyen como un tercer actor.

En ese interjuego, los centros fueron visualizados en este periodo además, como actores con quien entablar diálogo desde organismos de Derechos Humanos y desde espacios jerárquicos de gestión del Ministerio de Justicia de la Jurisdicción. Es decir que se vio a las y los universitarios detendidos organizados como potenciales aliados para incidir en la cotidianeidad de las unidades penales desde adentro y aportar a mejorar las condiciones de vida de la cárcel.

Una de las acciones explicitas que se pueden reconocer fueron las reuniones virtuales con los centros o algún/os referentes de los centros de la jurisdicción con representantes de organismos y Ministerio y por otro lado, reuniones virtuales periódicas con referentes de programas de diferentes universidades. Estos espacios además permitieron mayor proximidad entre esos organismos con las universidades a la vez que recibir de primera mano información de lo que pasaba en las unidades penales. Se crearon algunos canales de diálogo que hasta ese momento no habían existido o eran mucho más acotados, así como la posibilidad del reconocimiento y de intercambios de los centros universitarios entre sí. Estos vínculos establecieron diálogos y aperturas desde y hacia el Ministerio de Justicia para informar y demandar res-

7 Se hace referencia a la Resolución Tribunal de Casación Penal. Expediente 5/2020. 
puestas institucionales y políticas de gestión comunes para los espacios universitarios. De estas reuniones surgió un protocolo que permitió el regreso a las aulas de quienes estaban realizando estudios superiores ${ }^{8}$ que se puso en acto a principios del mes de octubre. Este marco legal impulsó y fortaleció el regreso de las y los universitarios a las aulas, más allá de la política de apertura o cierre que cada director de unidad hubiera impuesto y se convirtió en una herramienta de demanda y presión desde las Universidades al SPB.

Algunas escenas que nos develan "el otro lado" del muro en pandemia

Los centros universitarios en lo que va de la pandemia han sido un pilar fundamental de lo que es la educación y lo que ha sido el acceso a la justicia dentro de la cárcel. (Franco para Telarañas/ programa $\mathrm{N}^{\circ} 26$ - 14/12/20).

Nos proponemos aquí desarmar la idea de mirar solo "desde arriba", es decir desde el sistema, para indagar los modos en que se despliegan los territorios "desde abajo", la construcción de esa historia y relevar en lo no documentado algunos hilos que permiten comprender más ajustadamente las tensiones en juego. Entender qué se disputa en cada espacio a partir de los juegos de lo posible que entablan los actores. Entendemos que en las unidades penales los espacios de concreción de las políticas centrales, donde se dan las tensiones entre la subordinación y la autonomía. Y donde quienes tienen menor espacio para definir las reglas despliegan tácticas para lograr objetivos propios o colectivos.

La moneda corriente en el manejo de la cotidianeidad por parte de los agentes del SPB es la discrecionalidad, intercambio de favores por sometimiento, la cooptación y la dominación a través del castigo y la violencia. Además cabe recordar que la cárcel mantiene buena parte de su vida cotidiana por la labor de detenidos y detenidas que gestionan el funcionamiento y orden de pabellones, y los trabajos de mantenimiento y sostén de la vida intramuros.

Se ha relevado en investigaciones precedentes que el gobierno de la cárcel es posible por la participación directa de los mismos detenidos, como es el caso de los limpieza (ÁNGEL 2016) en las cárceles bonaerenses y la presencia de pabellones religiosos (MANCHADO 2018), que en la provincia de Buenos Aires se los conoce como Ministerio (Ángel 2016) o los hermanitos como hemos podido relevar en campo, cuya creciente expansión es sorprendente9.

Algunos aspectos que permiten rápidamente identificar de qué se tratan estos modos de tercerización del manejo de la población por parte de las fuerzas de seguridad a la propia población detenida, en particular el limpieza:

Si bien técnicamente el termino corresponde a la persona que se ocupa del aseo de la estructura edilicia, en realidad refiere a quien lleva el orden en el pabellón y otros espacios de la cárcel. El papel político que comienza a jugar esta figura es un fenómeno que data de varios años en la historia del mundo carcelario, pero que se ha mantenido oculto y que ha sido tratado muy poco en el espacio académico.

Llegar a ser limpieza equivale a llegar al poder y se vuelve visible a través del ejercicio de la violencia. Las personas que acceden a este rol tienen gran capacidad de negociación ante las altas autoridades de la institución penitenciaria y, además, garantizan el orden entre los internos de la cárcel. Depende de los limpiezas la política que se lleva en algunos lugares al interior de la cárcel. Por lo tanto, cada liderazgo de un limpieza va a conformar una política diferente. (ÁNGEL, 2016, p.132)

\section{$(\ldots)$}

La legitimidad de las altas autoridades de la institución a este tipo de prácticas violentas configuran la condición necesaria para la expansión y estabilización de una forma de gobierno tumbera, debido a que permite y respalda el despliegue y dominio territorial. (ÁNGEL, 2016, p. 134)

Respecto de los pabellones de Ministerio "regula el orden a través de ceremonias religiosas, en las cuales el limpieza actúa como un mediador pacífico, “un obrero de Dios" (ANGEL, 2016, p.316) y

Actualmente el sistema carcelario de la Provincia de buenos Aires es un sistema en crisis. Los dos vectores más persistentes de este proceso son la superpoblación de los pabellones y la consecuente des-

8 Se hace referencia a "Protocolo para garantizar la continuidad pedagógica universitaria en contexto de prevención del Covid-19", aplicable en el ámbito de todas las Unidades. RESO-2020-1836-GDEBA-SPBMJYDHGP 08/10/20. Servicio Penitenciario Bonaerense.

9 En una de las unidades penales de la zona centro de la PBA se releva más de la mitad de los pabellones como población evangelista. 
pacificación, que trastoca los niveles de violencia preestablecidos entre los internos y las estrategias de intervención de las autoridades penitenciarias. En este marco de redefinición de las reglas de juego cobra relevancia la presencia religiosa de los evangélicos, en tanto grupo mediador entre los reclusos y las autoridades con diferentes grados de eficacia, los pabellones cristianos intentan producir una nueva síntesis de convivencia que contemple la canalización de demandas internas con el mantenimiento del orden institucional (...) En la medida que se multiplica la población son más necesarias las figuras que regulen y ordenen ciertos espacios. De tal forma, se pone en evidencia que las restricciones del servicio penitenciario hacia estos pabellones o figuras de liderazgo son mínimas (ALGRANTI, 2011, p. 56 citado en ANGEL, 2016, p. 136)

La propuesta ahora es mirar por el ojo de la aguja que son los Centros Universitarios ${ }^{10}$ de qué modo esos estudiantes organizados pudieron por un lado relatar y por otro lado dar respuesta, a la situación que se vivía en las unidades penales en ese período.

El registro de relatos y relevamiento que se hizo en esos primeros meses de aislamiento dan idea de la desesperación, falta de respuestas e información, y como salida la violencia incitada desde las propias personas que eran responsables de la vida de detenidos y detenidas y como práctica regular de gobernabilidad de la prisión.

Es allí donde aparece otro norte: la participación que los diferentes centros universitarios en diferentes unidades penales de la Provincia tuvieron en este período. En modo directo se referirá aquí a centros universitarios donde la UNICEN desarrolla actividades académicas, de extensión y de investigación y en particular a uno, sobre el que nos enfocaremos a continuación para analizar el entramado que se da en tiempos de ASPO.
Primera escena: Incitar a la violencia de los cuerpos para gobernar

Dos internos que trabajan en el comedor de los funcionarios, uno de ellos sufre un cuadro gripal y levanta temperatura, desde el pabellón donde se encuentra alojado, se le aconseja ir a Sanidad, aun sabiendo que para ser atendidos tienen que pedirles a un jefe por favor, [ya que] para llegar a sanidad se debe recorrer un pasillo donde hay oficinas en las cuales trabajan los oficiales del SPB. Al ver al interno que iba a pasar por ahí, salieron corriendo de sus puestos de trabajo, nos perdimos de filmarlos lástima. Este hecho el interno no lo dejo pasar, se usó para ganar adeptos para la huelga, sin éxito, lo notable fue, la incitación de los funcionarios para que aíslen al enfermo y al compañero si no que armen quilombo. Lo que no pensaron es que si estaba contagiado el interno era por que alguno de ellos lo había contraído y tendrían que ser aislados todos los del turno" - ( R.R. Mayo 2020) $)^{11}$

En este relato lo que se quiere recuperar es la escena del manejo de la enfermedad en las unidades penales: de dos personas detenidas que se desempeñaban como auxiliares en el comedor del personal presentaron síntomas compatibles al COVID 19. El personal penitenciario responde por un lado con la huida (salen corriendo de sus oficinas para no exponerse) y desde el plano informal incitan a sumarse a un llamado a huelga general de presos que estaba circulando en la provincia motorizada por las unidades penales de mayor concentración y cercanía geográfica a la cabecera provincial ${ }^{12}$.

Es en ese contexto que emergen diferentes manifestaciones de reclamos en cárceles del país y en particular en los meses de abril/mayo $2020^{13}$. En el período inicial del ASPO las Unidades Penales se denunciaba el hacinamiento, la falta de alimentos y atención de la salud, la ausencia de la respuestas por parte de la Justicia y la falta de recursos para enfren-

10 "Estos centros, se constituyen en el "ojo de la aguja" por el que la universidad tiene que enhebrar sus hilos para coser, para confeccionar sus diseños ya que es el espacio en el que lxs estudiantes organizados buscan tensionar a su favor a ambas instituciones. Y esto implica reconocer aspectos opacos o silenciados con los que debe también disputar sentidos en y a la cárcel, en pos de su horizonte. Los y las estudiantes detenidos están tensionados por los intereses y disputas en el campo de encuentro de ambas instituciones y sus propias búsquedas. Y ese es el terreno sobre el que cotidianamente se produce el encuentro con los estudiantes" (UMPIERREZ, 2020B. Pág.85)

11 "Relatos en 1ra persona". Publicado en el sito de Facebook del Programa Educación en contextos de encierro, Facultad de Ciencias Sociales. UNICEN el 22/05/20 y recuperado en Newsletter 43 Facultad de Ciencias Sociales, 2020.

12 Se reclamaba que los Juzgados y Defensorías volvieran a sus tareas para el tratamiento de los pedidos; se avanzara con mediadas alternativas de prisión; atención sanitaria a quienes tenían enfermedades prevalentes, se concedieran arrestos domiciliarios. 13 Para ampliar esta idea ver RODRIGUEZ ALZUETA. Pandemonium: la cárcel es una bomba. https://rodriguezesteban.blogspot.com/2020/04/pandemonium-la-carcel-es-una-bomba-de.html. Diario digital El Cohete a la Luna, 19 de abril de 2020. 
tar la pandemia ${ }^{14}$. En esos conflictos hubo detenidos asesinados por el Servicio Penitenciario tal como se expuso en el inicio de este trabajo.

Recuperamos entonces la voz de otro estudiante que reflexiona sobre la labor de los centros en el período.

Segunda escena: Los centros universitarios, un pilar fundamental

Los centros universitarios en lo que va de la pandemia han sido un pilar fundamental de lo que es la educación y lo que ha sido el acceso a la justicia dentro de la cárcel." (Franco para Telarañas/ programa $\left.\mathrm{N}^{\circ} 26-14 / 12 / 20\right)$.

¿A qué refiere cuando dice que fueron el pilar fundamental?

La condición de asilamiento, encierro en el encierro y la falta de respuesta de la justicia hizo que Franco, en su necesidad de "hacer algo", definiera y me comunicara que iba a iniciar huelga de hambre en consonancia con lo que sucedía en otros penales de la provincia de Buenos Aires. En el lapso de dos días, me hace saber que "como universitario piensa que tiene que hacer otra cosa". Señala que la huelga de hambre en solitario no es la manera. Lo que plantea entonces es que es posible generar caminos de diálogo que permitan reducir la violencia en la cárcel.

A partir de ahí genera una serie de reuniones con compañeros de pabellón y del centro de estudiantes, solicita entrevista con autoridades y genera en conjunto con otros universitarios la posibilidad de auxiliar al resto de la población detenida con presentaciones legales para enviar a los juzgados que llevan sus causas en pos de obtener medidas alternativas a la prisión. (...) El centro universitario se constituyó en un interlocutor al interior de la cárcel. (Registro personal, abril 2020)

Son ahora las voces de otros de los universitarios, quienes eran parte de la producción de un programa de radio que se emitía semanalmente por la emisora de la Universidad. Allí relatan algunas circunstancias y formas que tomó la tarea asumida por los centros.
Tercera escena: Nos vinieron a buscar

- Adrian: Queremos contar lo que estamos haciendo desde el aula universitaria (...), me acuerdo un día de lluvia los chicos subiéndose a los techos en todas las unidades ${ }^{15}$, nos fueron a buscar a los universitarios, el Servicio Penitenciario nos fue a buscar diciendo si nosotros podíamos dar una mano respecto de los escritos judiciales. Tenemos un compañero, Jorge que estudia Derecho, que sabe mucho de escritos.

- Jorge (....) Como no hay procurador en la Unidad nos dieron la posibilidad de salir al Centro para hacerles los escritos a los pibes que no tienen acceso a su juzgado y darles una mano y ver como ellos pueden acercarse más a sus causas (...) prácticamente están abandonados y la justicia esta parada (Testimonio de Adrián y Jorge para Telarañas/ Programa $\mathrm{N}^{\circ} 2$ - 22 de junio 2020)

El primer tópico de interés en el que poner la mirada es el trabajo direccionado a la reducción de la violencia, la contención y gestión de la población detenida a través de la labor de redacción de escritos para que enviaran a sus juzgados con demandas específicas referidas a sus causas. A la par, se relevan escenas como las que se presentan en el inicio del apartado, en las que personal del SPB incita a la violencia y a la huelga de hambre como modo de expresión y de hacer oír su voz.

Respecto de la continuidad pedagógica la organización de los centros fue clave no solo en la tarea de retomar estudios universitarios propios sino además en ofrecer el apoyo a estudiantes de niveles educativos precedentes. Los universitarios tomaron un papel activo en la distribución y auxilio en pabellones de compañeros que asistían a otros niveles educativos, distribuyeron y retiraron materiales, ofrecieron ayuda para acompañar tareas y avanzar en la escolaridad en directa colaboración con coordinadores docentes del SPB.

Además, generaron por iniciativa propia otras actividades de promoción de la lectura como fue el caso de poner en marcha bibliotecas ambulantes ${ }^{16} \mathrm{en}$ una de las unidades penales que recorría pabellones

14 Para ampliar esto recomendamos ver Comunicado en Newsletter 43. Facultad de Ciencias Sociales. UNICEN 15 Para más información ver https://www.comisionporlamemoria.org/la-camara-de-apelaciones-y-garantias-de-quilmes-promueve-la-impunidad-penitenciaria/ 16 La Biblioteca móvil llegó a la Unidad penal a partir de la Capacitación “Mediadores del conocimiento" desarrollada por el Ministerio de Ciencia, tecnología e innovación, 2019. Actualmente se encuentra a cargo de estudiantes universitarios detenidos que desarrollan esta actividad entre otras de carácter pedagógicas destinadas al resto de la población. 
ofreciendo libros

En estos primeros días de trabajo el prejuicio que tenía y la idea inicial de que iban a ser pocos y de previsión de poco interés por pabellones, quedo en una demanda que superó las expectativas teniendo hasta una lista de espera. Quizás no se llegue a todos y todos no estén dispuestos en este momento a la lectura, pero es una opción al encierro extremo de esta crisis. Carlos / Relatos en 1ra persona $-28 / 05 / 20$

Asumieron además la tarea de estudiantes orientadores, una figura diseñada y legitimada en el seno de la Facultad de Ciencias Sociales desde el año 2018 para reconocer las tareas de apoyo académico que se realizaban hasta entonces de modo informal en las aulas universitarias y constituir ese desempeño en una tarea docente similar a la que desempeña un auxiliar alumno en la sede.

En el transcurso del ASPO se retomaron esas tareas en pabellones -sin muchos resultados- y luego en el aula a medida que los y las estudiantes fueron pudiendo regresar. Además, se transfirió esa forma de trabajo a un taller de extensión universitaria: con auxilio del docente se ofrecía oportunidades educativas a compañeros. Tal fue el caso del taller de Alfabetización informática que se realizó en los pabellones, a cargo de estudiantes universitarios supervisados por el docente y que tuvo como destinatarios a los detenidos que quisieran realizarlo. La vida en la cárcel en ese período se restringía a alguna hora en el patio y el resto a estar en el pabellón. Estas tareas distendieron las relaciones, llenaron las horas con propuestas proactivas, que además, ofrecían saberes valorados por parte de muchos detenidos y la Universidad certificaría.

Se puede advertir entonces una lectura crítica del contexto por parte de algunos universitarios, que reconocían que las prácticas violentas solo conducen o generan como respuesta más violencia. A su vez, entendían que era necesario involucrarse, más allá de saber cuáles podrían ser las consecuencias.

Durante varios meses ese grupo de estudiantes del que se presentaron los registros $-\mathrm{y}$ esto se repetía en otras cárceles- los centros universitarios fueron espacios de escucha, atención de recursos legales; envíos de pronto despacho con la anuencia de la Jefatura del SPB y con ello, fueron conteniendo los desbordes de violencia que podrían haberse sucedido. Y a partir de estas actividades estos estudiantes consiguen salir de los pabellones, ocupar de modo activo y propositivo su tiempo, recuperar una vida similar a la que llevaban antes de la pandemia a la vez que construir protagonismo, reconocimiento, respeto no solo al interior de la unidad penal sino ante responsables del Ministerio de Justicia y organismos de derechos humanos.

Con la puesta en marcha del protocolo de vuelta a las aulas, se dio una paulatina apertura para que los y las estudiantes fueran recuperando la posibilidad de asistir a los espacios de trabajo, acceder al uso de equipos informáticos, bibliotecas, etc. que se disponen allí para poder desarrollar carreras de grado.

Este protocolo se constituyó en una herramienta de presión en vistas a que es una orden que llega desde el Ministerio de Justicia para ser llevada adelante en las unidades, más allá de las decisiones que el director de unidad quisiera tomar.

$\mathrm{Y}$ en ese regreso, las presiones por ampliar la presencia de las y los universitarios en las aulas se conjugó con políticas de cierre de las unidades penales instaladas en nombre de la seguridad.

En ese contexto se habilitaron las visitas después de largos ocho meses de interrupción y el día previo a que se efectivizaran, se informa que no se autorizará ese ingreso de personas civiles. Esto devino en una reacción grave en algunas cárceles los días 31 de octubre y 1 de noviembre del 2020, tal como se presentó en el inicio de este artículo. Allí se registran hechos vandálicos sobre dos centros universitarios con sede en cárceles de la provincia e incitación a la violencia por parte de agentes del Servicio Penitenciario registrados con celulares por los propios detenidos.

En ese contexto, los días posteriores a esos episodios se trasladan a los responsables de la gestión del centro que tuvo mayor capacidad de organización y gestión al interior de las unidades penales en las que UNICEN trabaja. El grupo promotor ya había ido desarticulándose cuando se concretaron traslados pendientes en relación a la progresividad de la pena. Y se completó el desmantelamiento con el traslado compulsivo del último líder de centro, de modo intempestivo, despojándolo de sus pertenencias y sin causales que justificaran ese movimiento. Esto sucedió en toda la provincia tal como lo denunció el Comité 
contra la tortura "más de 1.500 personas sufrieron diferentes tipos de torturas (...) y traslados arbitrarios posteriores" (Gacetilla CPM 12/11/20).

\section{A modo de ataduras finales, otra piedra en el muro.}

Investigadora: Fue duro el año pasado, pero lo pudimos enfrentar

JC: Si, muy difícil acá adentro! Pero como digo yo, otra piedra en el muro. (Comunicación personal. JC, 38 años- estudiante universitario. Penal de máxima seguridad/ feb 2021)

Nos proponemos ahora poder poner en la mira las tensiones que atraviesan la vida cotidiana en la cárcel y la presencia de la Universidad allí, encarnada en los y las universitarios/as detenidos/as durante un largo período de incertidumbre, abandono y episodios de crisis y el encierro en el encierro.

Entendemos a la cotidianeidad como aquello que incluye "todo tipo de actividades que constituyen desde cada sujeto particular procesos significativos de reproducción social y apropiación cultural" (HELLER, 1970 citado en ROCKWELL, 1995, p.7) y que es el lugar y el tiempo en el que se materializan las políticas públicas en el territorio local y a la vez son resignificadas, resistidas, adoptadas en su seno.

Una pregunta que emerge en este recorrido es ¿Qué papel juegan los universitarios/as en la gestión de gobierno de la cárcel?

Se pudieron registrar prácticas sostenidas por los estudiantes universitarios en las que se relevan saberes aprendidos en su paso por la universidad. Lo que se observa de fondo es la disputa de sentidos entre ese grupo organizado y los modos de gestión de la cárcel: así como se acude a estudiantes universitarios para ser parte de la gestión de la cárcel en la medida que se constituyen en referentes de sus pares y conducen a la pacificación y gobierno, cuando la fuerza de esos grupos crece, devienen varias posibilidades: la cooptación, el traslado o la búsqueda de destrucción.

Lejos de pensar a la cárcel como un tiempo y un espacio como "caja negra", entre el encierro y la liberación de las personas detenidas, este análisis permite poner en luces y sombras algunas trazas en la subjetividad de quienes transitan por propuestas de la universidad, haciéndolas visibles. Y por otro lado advertir cómo esas formas de construir identidad en términos colectivos en la detención, impactan en el gobierno de la cárcel.

Tal como se expuso, el gobierno de la cárcel es posible por la participación en diferente forma por los mismos detenidos, como es el caso de los limpieza en las cárceles bonaerenses y la creciente presencia de pabellones religiosos, el ministerio o los hermanitos, y en ese mismo camino, en los últimos diez años han crecido exponencialmente la presencia en las cárceles de la provincia los universitarios.

Las acciones desde el CPM y Ministerio de Justicia para convocar a las universidades y generar un movimiento disruptivo, planteó puentes que permitieron generar alianzas. Se identificó y apuntaló a los Centros Universitarios y a sus referentes como actores que aportaran a la gubernamentalidad de la cárcel. ¿Podríamos pensar que fueron los estudiantes universitarios detenidos punta de lanza de un intento de reforma desde adentro que pusiera en jaque al orden interno o al menos pudieran traspasar los muros trayendo voces y relatos organizados de lo que sucedía?

En la tensión de esa construcción de fuerzas políticas, las formas de gobierno tradicionales de la cárcel asociadas a la represión y la violencia retornaron de modo extremo en la represión de los días 31 de octubre y primero de noviembre al incendiar el propio personal penitenciario dos centros de estudiantes, según consta en imágenes tomadas por detenidos que cuidaban las instalaciones. Durante el período del ASPO pudimos ver un proceso de construcción de poder y un final cruel pero anunciado: la dispersión de los actores en diferentes unidades penales señalando de modo tácito pero pretendidamente disciplinador con ese movimiento, que ya no corría peligro el orden interno dominante de la Unidad Penal.

Entendemos que el crecimiento numerario de los centros de estudiantes en diferentes unidades penales de la provincia consolida la emergencia de un nuevo actor social que construye otras tensiones en la vida cotidiana de la cárcel. Este actor social es colectivo y organizado, y a través de sus prácticas se incorporan e inyectan nuevos saberes a aquellos construidos en la detención, -los códigos que hay que respetar- a partir de su paso por la universidad.

Un indicador de este emergente -en medio 
de tanta confusión, angustia y desolación- es la capacidad de diálogo y de negociación alcanzada como grupo. Identificamos allí la grupalidad (DEL CUETO y FERNÁNDEZ, 2000) como un resorte que nuclea y sostiene a este colectivo de estudiantes detenidos en una situación crítica y extrema de aislamiento.

Esa grupalidad, entendida como una capacidad construida y sostenida colectivamente que permite canalizar la desesperación en un horizonte de bien común: acompañar a los más desamparados en la búsqueda de atención a sus derechos de acceso a la justicia y educación. No se trata de un liderazgo individual sino en el despliegue de fuerzas colectivas que enlazan al interior de pabellones con necesidades y búsquedas de sostén.

Remite a una construcción política que pone en tensión la propia cultura institucional, construyéndose por el término de unos meses en actores dinamizadores del espacio carcelar (CORREA, 2019), interlocutores con los detenidos en los pabellones. Y a diferencia de los limpieza o los hermanitos, colaboran con los agentes del servicio penitenciario, negocian, pero tienen lectura crítica y resisten ciertos patrones de dominación.

Se disputa aquí una de los organizadores que atraviesan la vida de la cárcel: ubicar a las y los detenidos en la tensión entre lo individual versus lo colectivo como construcción compartida de sentidos.

La puesta en marcha a principios del mes de octubre del Protocolo de vuelta a las aulas de universitarios se convirtió en una herramienta de demanda y presión desde las Universidades al SPB. Esto puede leerse en consonancia con el episodio que cierra el período analizado: los reclamos en varias cárceles cuando se suspendieron las visitas el 31 de octubre y primero de noviembre y el incendio de dos centros universitarios de manos de personal del propio SPB.

Como ataduras finales, se propone una reflexión respecto de la educación en sentido amplio y en la cárcel en particular. La educación ha sido históricamente el ámbito privilegiado de transmisión del saber y la cultura acumulada por los pueblos. Con el advenimiento del Estado moderno, los sistemas educativos fueron el dispositivo diseñado como política de Estado para llegar a toda la extensión de su terri- torio con las prescripciones del deber ser de ciudadanía.

De ese modo los Estados modernos buscaron consolidarse construyendo una identidad común y un arco de solidaridades que les permitiera sostenerse en el tiempo, apelando a la adhesión voluntaria de cada uno de sus habitantes sin necesidad de acudir a la fuerza para ejercer su gobierno. Como contrafigura no dicha, nunca fue para todos, nunca fue universal ese acceso más allá de los marcos legales o los discursos.

Reconocemos en el despliegue de la pedagogía como campo diferentes perspectivas que valen la pena distinguirse a los fines exclusivos de actualizar la idea que se trata de las pedagogías, múltiples y con enfoques contrapuestos. Es decir, no estamos refiriéndonos a la educación sino a múltiples educaciones posibles.

Si bien éste es un planteo que traspasa la problemática de la educación en privación de libertad, se constituye en un tema urgente para pensar la educación en este ámbito, en pleno avance de la nueva derecha (APPLE, 1996) a nivel global. La cárcel es parte de un entramado social, necesaria en el devenir del capitalismo depredador (GIROUX, 2013) y tal como plantea Wacquant, el neoliberalismo "es un proyecto político transnacional destinado a reconstruir el nexo del mercado, del Estado y de la ciudadanía desde arriba" y en esa reconstrucción "un aparato penal expansivo, intrusivo y proactivo" (WACQUANT, 2011, p.13-14) es parte central de la gestión de la población.

Vale aquí entonces introducir última pregunta respecto esa tensión que atraviesa a la educación en la cárcel: ¿se trata de un brazo blando que aporta a la dominación o es posible pensarla como parte de una cuña ${ }^{17}$ para incidir en procesos de liberación de grandes sectores sociales que devienen en población prisionizada como parte necesaria del avance neoliberal?

La educación y en particular las propuestas de las universidades en contextos de privación de libertad, pueden constituirse en los modos capilares de transformar la vida cotidiana de la cárcel. Pueden trabajar para convertirse en esa cuña que pueda hendirse y dividir la solidez de la cárcel. Pero esta será

17 Una cuña según el diccionario d la Real Academia Española es una "pieza de madera o de metal terminada en ángulo diedro muy agudo. Sirve para hender o dividir cuerpos sólidos, para ajustar o apretar uno con otro, para calzarlos para llenar alguna raja o hueco". 
una tarea muy desigual sin la presencia sostenida de agencias del Estado que demanden el cumplimiento de las normas preestablecidas.

\section{Agradecimientos}

Este trabajo ha sido posible gracias al financiamiento obtenido a través del proyecto 03- /PIO(38F) - SECAT-UNCPBA en el marco del Programa de Fortalecimiento de la Ciencia y Tecnología en Universidades Nacionales de la Secretaría de Políticas Universitarias.

\section{Referencias}

ANGEL Luis Alberto. El limpieza como articulador, garante del orden y regulador de la violencia en las cárceles bonaerenses. APP, Buenos Aires, 2016. Disponible en http://www.pensamientopenal.com.ar/ doctrina/44588-limpieza-articulador-garante-del-orden-y-regulador-violencia-carceles-bonaerenses

APPLE, Michel: El conocimiento oficial .España: Paidós, 1996.

CORREA Ana María: Producción de sentidos y subjetividades en el espacio carcelar. Acceso a justicia y a derechos. 15 años de investigación desde la perspectiva de los Derechos Humanos. Córdoba, Universidad Nacional de Córdoba, 2019.

DEL CUENTO Ana María y FÉRNANDEZ Ana María. El dispositivo grupal .En PAVLOVSKY E. y DE BRASI, J.C (Directores): Lo Grupal. Devenires. Historias. Galerna. Búsqueda de Ayllu. Buenos Aires, 2000. Pp.47-88.

DIAMANT, Ana; CAZAS, Fernando; DUHALDE, Mariela C. Formación docente, traza didáctica y subjetividad. Anuario de Investigaciones, vol. XXII. Universidad de Buenos Aires. Buenos Aires, Argentina, 2015. pp. 99-106.

FARES, Virginia Amalia. En busca del espacio perdido. Instituciones, Espacio y Subjetividad. En: Cuadernos de H Ideas, Vol. 4, Número 4. Dic. Disponible en http://perio.unlp.edu.ar/ojs/index.php/cps/index

GIROUX Henry. La Pedagogía crítica en tiempos oscuros. En: Revista Praxis educativa Vol. XVII, No 2, 13-26. Facultad de Ciencias Humanas. Universidad de La Pampa. http://www.fchst.unlpam.edu.ar/ojs/ index.php/praxis

GONZÁLEZ ALVO Luis. Sobre los descensos de la población encarcelada en la Argentina. Algunas observaciones desde la historia de la prisión.En: Revista de Historia de las Prisiones no 10 (Enero-Junio 2020), pp. 122-132 INIHLEP - ISSN: 2451-6473

LAPASSADE, George (1977 [1999]). Grupos, Organizaciones e Instituciones. 3era edición. Barcelona: Gedisa

MANCHADO Mauricio 'Hacen un buen trabajo dentro del servicio. Las ocupaciones estratégicas del dispositivo religioso pentecostal en las prisiones argentinas: Revista Temas y Debates, año 22, número 35, enero-junio 2018, pp. 95-112.

MANERO BRITO, Roberto. Introducción a los conceptos básicos del Análisis Institucional: Sujeto, Subjetividad y Cultura, Número 5. Abr. Esc. Psicología UARCIS, Santiago de Chile, pp. 6-20, 2013.

UMPIERREZ Analia. Aulas y estudiantes universitarios organizados en la cárcel: un territorio en tensión.: Educação e Cultura Contemporânea. Rio de Janeiro: Universidad Estacio de Sá. 2020 vol.17 nº 48 . p81 - 103.

B. Disputar sentidos a la cárcel: Prisiones contemporáneas. UNCa- Córdoba, Editorial Tinta Roja. 2020. p.79-102

C. Trazas de una propuesta educativa y artística en cárceles: Temas em Educacao. João Pessoa: Estudios Graduados e Investigaciones (PRPG). 2020 vol. $29 n^{\circ} \cdot$ pp. $228-248$

D. Vivir la pandemia en la cárcel. Relatos en primera persona: UMPIERREZ, CHIPONI y RUBIN: Dossier especial. El encierro en el encierro. Reflexiones e informes iniciales sobre cárcel, universidad y prácticas políticas en contexto de pandemia. Newsletter. Facultad de Ciencias Sociales. Unicen. Disponible en: https://www.soc.unicen.edu.ar/index.php/ categoria-editorial/277-newsletter/n-43/4020-newsletter-n-43-dossier-especial-reflexiones-e-informes-iniciales-sobre-carcel-universidad-y-practicas-politicas-en-contexto-de-pandemia

ROCKWELL, Elsie; EZPELETA, Justa. La escuela, relato de un proceso de construcción inconcluso. Comisión de Educación de Clacso, Fundación Carlos 
Chagas, Sao Paulo, Brasil. Revista Novedades Educativas N95, Nov. 1998. Buenos Aires, Argentina.Pp56

WACQUANT, Loïc; ROLDÁN, Diego P.;PASCUAL, Cecilia M. Forjando el Estado Neoliberal: Workfare, Prisonfare e Inseguridad Social: Prohistoria, Vol. 16. Rosario, Argentina. jul./dic.2011

16 Recuperado en 31 de octubre de 2016, de http:// www.scielo.org.ar/scielo.php?script=sci_arttext\&pi$\mathrm{d}=$ S1851-95042011000200006\&lng=es\&tlng=es.

\section{$\underline{\text { Otras fuentes }}$}

Comisión Provincial por la Memoria. Informes anuales del Comité contra la Tortura. Disponibles en https://www.comisionporlamemoria.org/

Nota "CUSAM: tras la represión, la reconstrucción" 4/11/20 - disponible en https://www.marcha.org. ar/a-reconstruir-el-cusam

Programa de radio Telarañas disponible en Facebook:

Telarañas. Voces en libertad 